\title{
Effect of Carbon Content on Bainite Transformation Start Temperature in Low Carbon Fe-9Ni-C Alloys
}

\author{
Hiroyuki KAWATA, ${ }^{1) *}$ Kazuki FUJIWARA ${ }^{2)}$ and Manabu TAKAHASHI ${ }^{1)}$ \\ 1) Steel Research Laboratories, Nippon Steel and Sumitomo Metal Corporation, 20-1 Shintomi, Futtsu, Chiba, $293-8511$ \\ Japan. \\ 2) Advanced Technology Research Laboratories, Nippon Steel and Sumitomo Metal Corporation, 1-8 Fuso-Cho, Amagasaki, \\ Hyogo, 660-0891 Japan.
}

(Received on April 25, 2017; accepted on June 5, 2017; J-STAGE Advance published date: August 24, 2017)

\begin{abstract}
Bainite in steel is an industrially useful structure. However, the controlling factor of its transformation start point is not known clearly. In this study, to clarify the effect of carbon content on the bainite transformation start temperature $\left(B_{s}\right)$, we evaluated the dilatation curve and the microstructure in low carbon Fe-9Ni alloys. As a result, $B_{s}$ decreased with increasing of carbon content. Furthermore, the driving force of partitionless transformation from fcc to bcc at $B_{s}$, which was calculated considering nickel segregation, was approximately constant at $400 \mathrm{~J} / \mathrm{mol}$ in all alloys. This value is consistent with the driving force required for partitionless growth of ferrite, as reported in a previous study. This consistency suggests that $\mathrm{B}_{\mathrm{s}}$ depends on the martensitic growth behavior of lath-shaped ferrite, which is determined by the supercooling starting from the $T_{0}$ line.
\end{abstract}

KEY WORDS: bainite; martensite; phase transformation; driving force.

\section{Introduction}

Bainite in steel is a very useful structure because it has a relatively high strength along with good formability and toughness. Many types of high strength steels contain bainite; therefore, it is important to accurately know the bainite transformation start temperature $\left(\mathrm{B}_{\mathrm{s}}\right)$.

Three definitions have been proposed for $\mathrm{B}_{\mathrm{s}}{ }^{1-4)}$ The first one defines $B_{s}$ as the upper critical temperature for the formation of bainite; ${ }^{1-3)}$ this temperature is called microstructural- $\mathrm{B}_{\mathrm{s}}{ }^{3)}$ Figure 1 shows a schematic for this $\mathrm{B}_{\mathrm{s}}$ through a time-temperature-transformation (TTT) diagram and continuous-cooling-transformation (CCT) diagram for a low carbon alloy. ${ }^{1,2,4)}$ As shown in Figs. 1(a) and 1(b), this temperature appears at the terrace of the diagrams for alloys in which the C-curve of diffusion transformation (ferrite and pearlite) is much slower than that of bainite transformation. The second definition is that $\mathrm{B}_{\mathrm{s}}$ is the upper limiting temperature for an incomplete bainite transformation in a TTT diagram; ${ }^{4)}$ this temperature is called kinetic- $\mathrm{B}_{\mathrm{s}}$. Although kinetic- $\mathrm{B}_{\mathrm{s}}$ appears in alloys that contain $\mathrm{Mo},{ }^{5} \mathrm{Cr},{ }^{6)} \mathrm{Mn},{ }^{7)}$ and $\mathrm{Nb}^{8}{ }^{8}$ its appearance in low-alloyed $\mathrm{Fe}-\mathrm{C}$ alloys, ${ }^{2,7-9)}$ in which the C-curves of bainite and diffusion transformation (ferrite and pearlite) overlap extensively, as shown in Fig. 1(c), is unclear. The third definition is that $B_{s}$ is the transformation start temperature during a discrete heat treatment. ${ }^{10-12)}$ Although it is valuable for steel making, $B_{\mathrm{s}}$

\footnotetext{
* Corresponding author: E-mail: kawata.z84.hiroyuki@jp.nssmc.com DOI: http://dx.doi.org/10.2355/isijinternational.ISIJINT-2017-239
}

depends on many heat treatment conditions that affect the pre-existent microstructure of bainite at the start of its transformation (e.g., cooling rate). In this study, we used the first definition of $\mathrm{B}_{\mathrm{s}}$; this $\mathrm{B}_{\mathrm{s}}$ corresponds to the upper limit of the partitionless growth of ferrite. ${ }^{1)}$

Several models have been proposed for determining $\mathrm{B}_{\mathrm{s} .}{ }^{1,2,4)}$ The most reliable model is Bhadeshia's model. ${ }^{1)}$ It suggests that $B_{s}$ is parallel to and below the $T_{0}$ temperature, at which fcc and bec of the same composition have the same free energy. In the model, bainite transformation is displacive transformation and requires the driving force of martensitic transformation, which is larger than that required for the displacive growth of bainitic ferrite. This model can explain some results showing a decrease in $\mathrm{B}_{\mathrm{s}}$ with increasing carbon content. ${ }^{10,13,14)}$ However, in some results, ${ }^{2,9,15,16)}$ it shows that $\mathrm{B}_{\mathrm{s}}$ does not depend or slightly depends on the carbon content. Tsuzaki et al. ${ }^{2)}$ proposed another model for the $\mathrm{B}_{\mathrm{s}}$ of low carbon steels. They assumed that a $\mathrm{B}_{\mathrm{s}}$ independent from carbon content corresponds to the martensite transformation start temperature $\left(\mathrm{M}_{\mathrm{s}}\right)$ in ultra low carbon steel and proposed that the nucleation of bainitic ferrite starts in the carbon-free regions of low carbon steel. However, there is no evidence for the existence of carbon-free regions, neither experimentally nor theoretically. Therefore, these models cannot explain the $B_{s}$ above the $T_{0}$ temperature in high carbon steels. ${ }^{3,9,17)}$

The aim of this study is to clarify the mechanism of bainite transformation start. To this end, we evaluate the effect of carbon content on $\mathrm{B}_{\mathrm{s}}$ in $\mathrm{Fe}-9 \mathrm{Ni}$ alloys, ${ }^{2,18)}$ in which nickel does not exhibit a solute drag like effect. ${ }^{6)} \mathrm{We}$ 

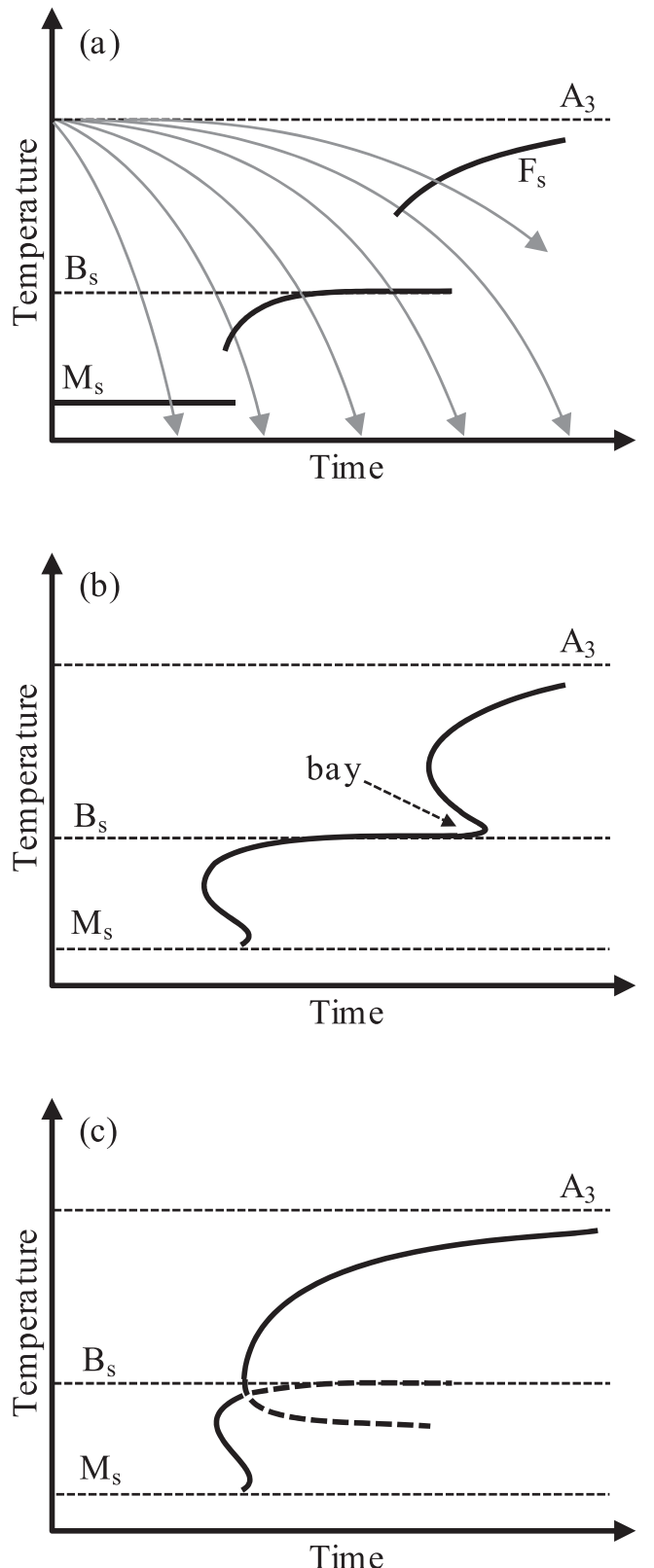

Fig. 1. Transformation start line on the schematic CCT and TTT diagrams for low carbon alloys. (a) CCT diagram wherein the ferrite and bainite regions are well separated. ${ }^{1)}$ (b) TTT diagram wherein the ferrite and bainite regions are well separated. ${ }^{1,2,4)}$ (c) TTT diagram in which the ferrite and bainite regions extensively overlap., ${ }^{2,4)}$

focus on low carbon alloys in this paper. We define that bainite, which transforms just below $\mathrm{B}_{\mathrm{s}}$, contains a group of lath-shaped ferrites with/without cementite. This definition confirms to the upper bainite categorized by Ohmori et al. ${ }^{19)}$

\section{Experimental Procedure}

Table 1 shows the chemical compositions and $\mathrm{T}_{0}$ temperatures of the five $\mathrm{Fe}-9 \mathrm{Ni}$ alloys used in this study. To avoid ferrite transformation around $\mathrm{B}_{\mathrm{s}}$, Alloys $\mathrm{A}, \mathrm{B}$, and $\mathrm{C}$ contained a small amount of boron. Alloy A was an ultra low carbon alloy containing 0.0031 mass $\% \mathrm{C}$. Alloys B and D contained 0.05 mass $\% \mathrm{C}$, and Alloys $\mathrm{C}$ and $\mathrm{E}$ contained 0.10 mass $\%$ C. Other elements in these alloys were present in a very small amount. The $\mathrm{T}_{0}$ temperatures shown in Table 1 were calculated via Thermo-Calc using the TCFE8 material database. In the calculation, we considered only $\mathrm{Fe}, \mathrm{C}$, and $\mathrm{Ni}$ and neglected other elements.

Ingots of the alloys melted in vacuum were heated at $1523 \mathrm{~K}$ and hot-rolled over $1173 \mathrm{~K}$ to make plates with a $3 \mathrm{~mm}$ thickness. These plates were grinded to remove the decarburized layer around both surfaces and cold-rolled to sheets with a $1 \mathrm{~mm}$ thickness. These sheets were cut to small specimens with dimensions of $10 \mathrm{~mm} \times 80 \mathrm{~mm}$.

These specimens were heated via electrical heating and cooled by $\mathrm{N}_{2}$ or He gases. The transformation behavior during the heat treatment was evaluated based on a dilatation curve obtained using a laser displacement meter.

We performed two tests. The first test was a continuous cooling test. The specimens were austenitized at $1473 \mathrm{~K}$ or $1223 \mathrm{~K}$ for $60 \mathrm{~s}$. To save time, the cooling rate was changed twice for each specimen. After austenitization, the specimens were cooled to just above $\mathrm{A}_{\mathrm{e} 3}$, which was calculated, at a relatively high cooling rate, i.e., $20 \mathrm{~K} / \mathrm{s}$. Below $\mathrm{A}_{\mathrm{e} 3}$, the specimens were cooled at several cooling rates between 0.01 and $300 \mathrm{~K} / \mathrm{s}$ until the transformation was complete. Then, they were cooled at a rate of $30 \mathrm{~K} / \mathrm{s}$.

The second test was an isothermal holding test. The specimens were austenitized at $1473 \mathrm{~K}$ or $1223 \mathrm{~K}$ for $60 \mathrm{~s}$ and then cooled to several temperatures at $30 \mathrm{~K} / \mathrm{s}$. The holding time was changed according to the transformation behavior. After holding, the specimens were cooled at $30 \mathrm{~K} / \mathrm{s}$.

The microstructures etched with nital were observed using an optical microscope (OM). In order to avoid the influence of the surface, the observation field was limited to the inside of the steel plate, and observation was not carried out in the range of $0.13 \mathrm{~mm}$ depth from the surface. For all specimens, we observed over 20 prior austenite grains in the observation field. Especially, in the specimens held isothermally around $\mathrm{B}_{\mathrm{s}}$ for short time, which containing small amount of ferrite and/or bainite, we observed the whole observation field.

Table 1. Chemical compositions and $\mathrm{T}_{0}$ temperatures of the alloys used in this study.

\begin{tabular}{|c|c|c|c|c|c|c|c|c|c|c|}
\hline \multicolumn{10}{|c|}{ Chemical compositions/mass $\%$} & \multirow{2}{*}{$\begin{array}{c}\mathrm{T}_{0} / \mathrm{K} \\
\text { (calcurated) }\end{array}$} \\
\hline Alloy & & $\mathrm{C}$ & $\mathrm{Si}$ & $\mathrm{Mn}$ & $\mathrm{P}$ & S & $\mathrm{Ni}$ & B & $\mathrm{N}$ & \\
\hline A & \multirow{3}{*}{ boron added } & 0.0031 & $<0.01$ & 0.02 & 0.005 & 0.001 & 9.06 & 0.0023 & 0.0013 & 884 \\
\hline B & & 0.052 & $<0.01$ & 0.02 & 0.005 & 0.001 & 9.08 & 0.0024 & 0.0014 & 863 \\
\hline $\mathrm{C}$ & & 0.094 & $<0.01$ & 0.02 & 0.005 & 0.001 & 9.09 & 0.0024 & 0.0017 & 846 \\
\hline $\mathrm{D}$ & \multirow{2}{*}{ boron free } & 0.050 & $<0.01$ & 0.01 & 0.005 & 0.001 & 9.03 & $<0.0003$ & 0.0017 & 865 \\
\hline $\mathrm{E}$ & & 0.099 & $<0.01$ & 0.01 & 0.005 & 0.001 & 9.06 & $<0.0003$ & 0.0017 & 845 \\
\hline
\end{tabular}




\section{Results}

\subsection{Ultra Low Carbon Fe-9Ni-B Alloy}

Figure 2 shows the dilatation curves during continuous cooling with various cooling rate after austenitization at $1473 \mathrm{~K}$ for Alloy A. Under rapid cooling, i.e., faster than $10 \mathrm{~K} / \mathrm{s}$, the volume expansion corresponding to transformation started at $\sim 765 \mathrm{~K}$ and finished at $\sim 700 \mathrm{~K}$. On the other hand, at a cooling rate of $10 \mathrm{~K} / \mathrm{s}$ or less, the expansion started at $\sim 833 \mathrm{~K}$. Alloy A showed two distinct transformation temperatures, $765 \mathrm{~K}$ and $833 \mathrm{~K}$ corresponding to grey lines in Fig. 2.

Figure 3(a) shows an OM image of the Alloy A specimen cooled at $200 \mathrm{~K} / \mathrm{s}$, in which the transformation occurred between $765 \mathrm{~K}$ and $708 \mathrm{~K}$. The prior austenite grain in the center of Fig. 3(a) consists of some packets containing many parallel laths, as illustrated in Fig. 3(b). This morphological feature is similar to that of a typical lath martensite structure $^{20)}$ and upper bainite structure. ${ }^{21)}$

Figure 3(c) shows an OM image of the Alloy A specimen cooled at $1 \mathrm{~K} / \mathrm{s}$. In this specimen, phase transformation started at $834 \mathrm{~K}$ and finished at $753 \mathrm{~K}$. Most of this specimen transformed above $765 \mathrm{~K}$, which was the transformation start temperature during the rapid cooling of Alloy A. However, in this image, the microstructure is similar to that shown in Figs. 3(a) and 3(b). The prior austenite grain illustrated in Fig. 3(d) consists of some packets, similarly.

In other words, microstructures having the same morphological characteristics were generated at two different transformation start temperatures. The difference between these temperatures was $\sim 70 \mathrm{~K}$. These two temperatures likely correspond to $\mathrm{M}_{\mathrm{s}}$ and $\mathrm{B}_{\mathrm{s}}$.

To clarify the transformation behavior around $833 \mathrm{~K}$, which is a high transformation temperature, we performed an isothermal holding test. Figure 4 shows the dilatation curves during isothermal holding at several temperatures. The vertical axis shows normalized dilatation, which is expressed by the following equation:

$$
\mathrm{f}=\frac{\mathrm{D}-\mathrm{D}_{\gamma}}{\mathrm{D}_{\alpha}-\mathrm{D}_{\gamma}}
$$

where $\mathrm{f}$ represents normalized dilatation, $\mathrm{D}$ represents dila-

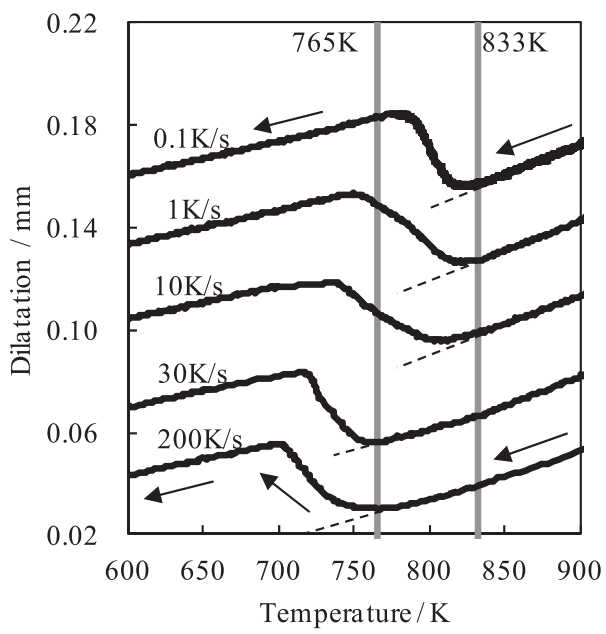

Fig. 2. Dilatation curves during continuous cooling in the Alloy A specimen.
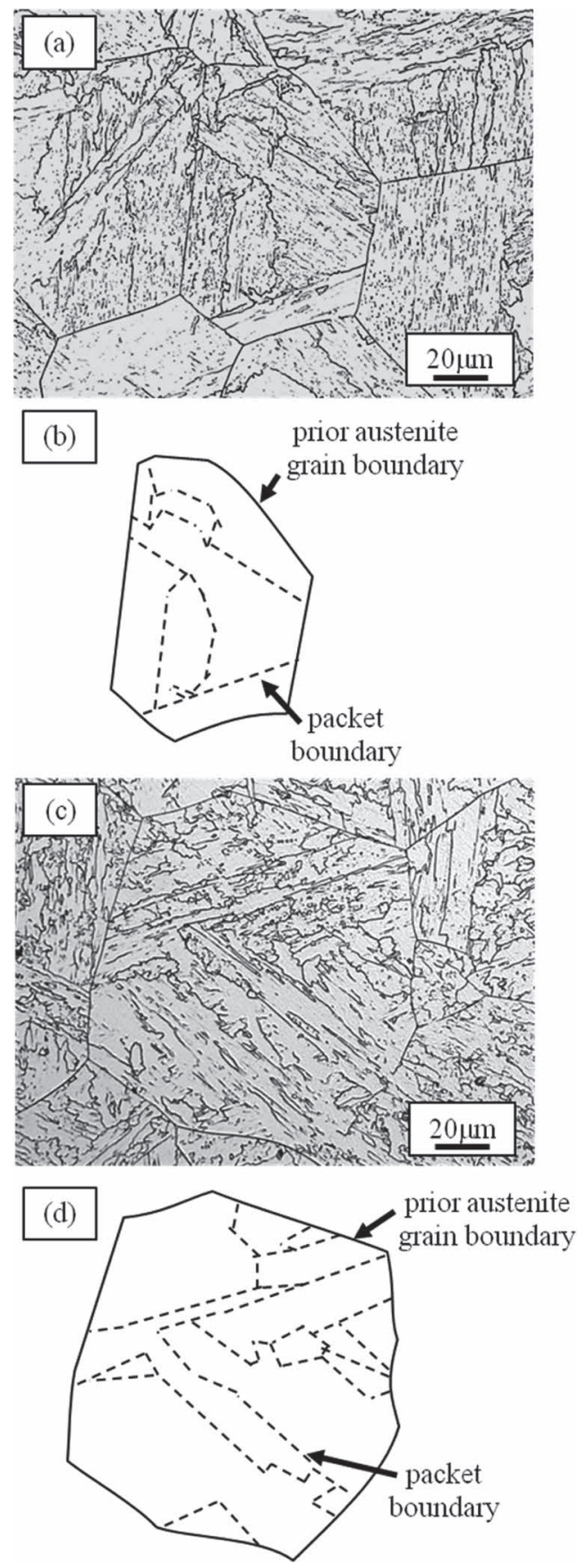

Fig. 3. Microstructure of the Alloy A specimens cooled continuously at (a) (b) $200 \mathrm{~K} / \mathrm{s}$, and (c) (d) $1 \mathrm{~K} / \mathrm{s}$. (a) (c) OM image. (b) (d) Schematic image of the prior austenite grain in OM image.

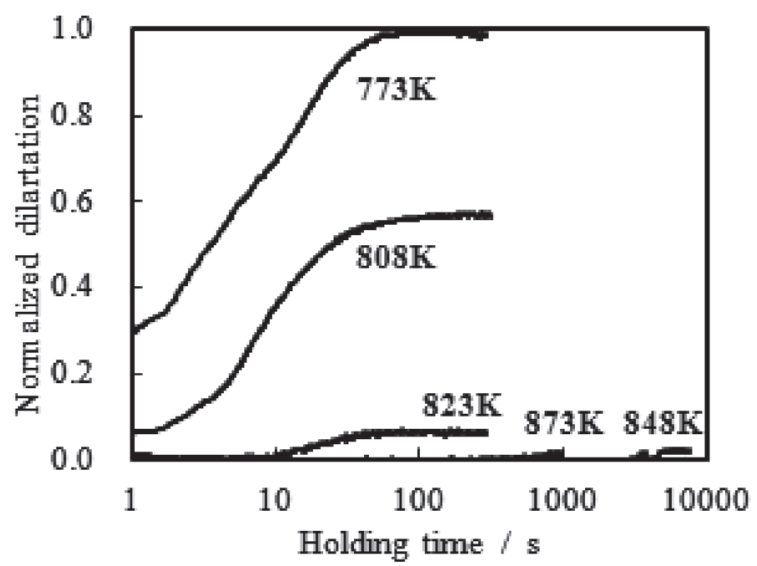

Fig. 4. Dilatation curves during isothermal holding in the Alloy A specimen. 
tation, and $\mathrm{D}_{\alpha}$ and $\mathrm{D}_{\gamma}$ represent the presumed dilatations for a full ferrite structure and an austenite structure at the holding temperature, respectively.

Below $833 \mathrm{~K}$, the volume expansion corresponding to transformation started within $10 \mathrm{~s}$ at the latest and stopped at around $100 \mathrm{~s}$. At $808 \mathrm{~K}$ and $823 \mathrm{~K}$, an incomplete transformation occurred clearly. On the other hand, the transformation just above $833 \mathrm{~K}$ progressed very slowly. Moreover, the incubation period at $848 \mathrm{~K}$ was longer than that at 873 $\mathrm{K}$. This means that there is a bay around $833 \mathrm{~K}$ in the TTT diagram.

Figure 5 shows an OM image captured in the early stage of transformation during isothermal holding. In the specimen held at $848 \mathrm{~K}$ for $10000 \mathrm{~s}$ (Fig. 5(a)), there are some allotriomorphic ferrite grains arrowed in an image over prior austenite grain boundaries. On the other hand, in the specimens held below $833 \mathrm{~K}$ (Figs. 5(b) and 5(c)), the microstructures consist of laths and there are no ferrite grains. This indicates that the shape of ferrite changed from
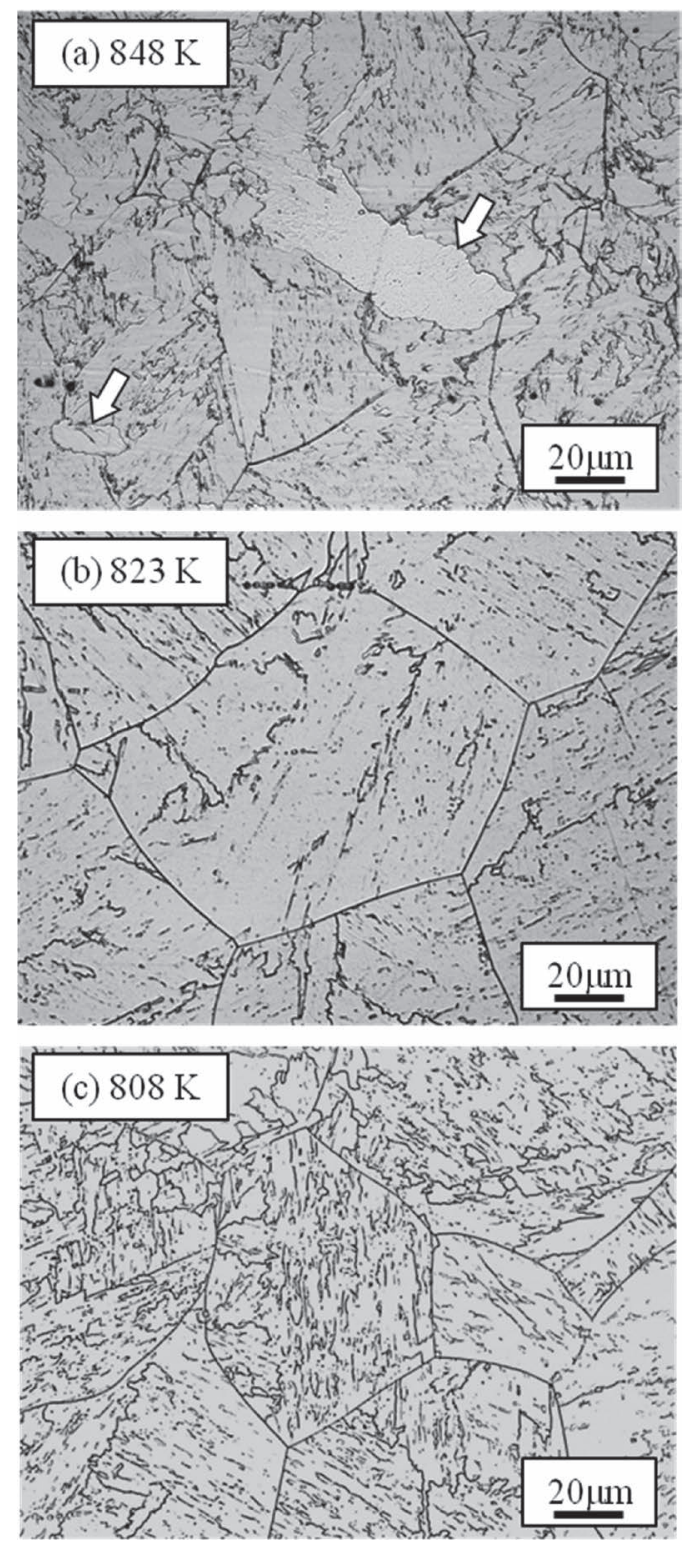

Fig. 5. OM images of the Alloy A specimen held isothermally (a) at $848 \mathrm{~K}$ for $10000 \mathrm{~s}$, (b) at $823 \mathrm{~K}$ for $600 \mathrm{~s}$, and (c) at 808 $\mathrm{K}$ for $500 \mathrm{~s}$. an allotriomorph to a lath with decreasing transformation temperature from $833 \mathrm{~K}$, which is a high transformation start temperature.

\subsection{Low Carbon Fe-9Ni-B Alloys}

Figure 6 shows the CCT diagrams for Alloys B and C, which contain a small amount of carbon with boron. The transformation start points during continuous cooling after austenitization at $1473 \mathrm{~K}(\mathrm{O})$ clearly show the $\mathrm{M}_{\mathrm{s}}$ of these alloys. However, $\mathrm{B}_{\mathrm{s}}$ is not clear from these points because the velocities of bainite transformation in them were smaller than that in Alloy A. To accelerate the transformation, we decreased the austenitization temperature to decrease the size of prior austenite grains. The transformation start points of the specimens austenitized at $1223 \mathrm{~K}(\boldsymbol{\Delta})$ show clear terraces between $M_{\mathrm{s}}$ and $\mathrm{T}_{0}$ (Fig. 6).

Figure 7 shows $\mathrm{OM}$ images of the specimens of Alloys $\mathrm{B}$ and $\mathrm{C}$ held isothermally just below the terrace for a short time. The volume fractions that were transformed in these specimens were assumed to be less than $5 \%$ based on the dilatation curves. In the Alloy B specimen held at $798 \mathrm{~K}$ for $1000 \mathrm{~s}$ (Fig. 7(a)), a group of lath-shaped ferrites on a prior austenite grain boundary was observed. This ferrite group was surrounded by lath martensite layer, which transformed during quenching after isothermal holding. Moreover, no cementite was observed in or around this ferrite group. This ferrite group is called B-I type upper bainite. ${ }^{19)}$

The same microstructure appears in the Alloy $\mathrm{C}$ specimen held at $783 \mathrm{~K}$ for $10000 \mathrm{~s}$ (Fig. 7(b)). The images in this figure indicate that the terraces in the CCT diagrams are
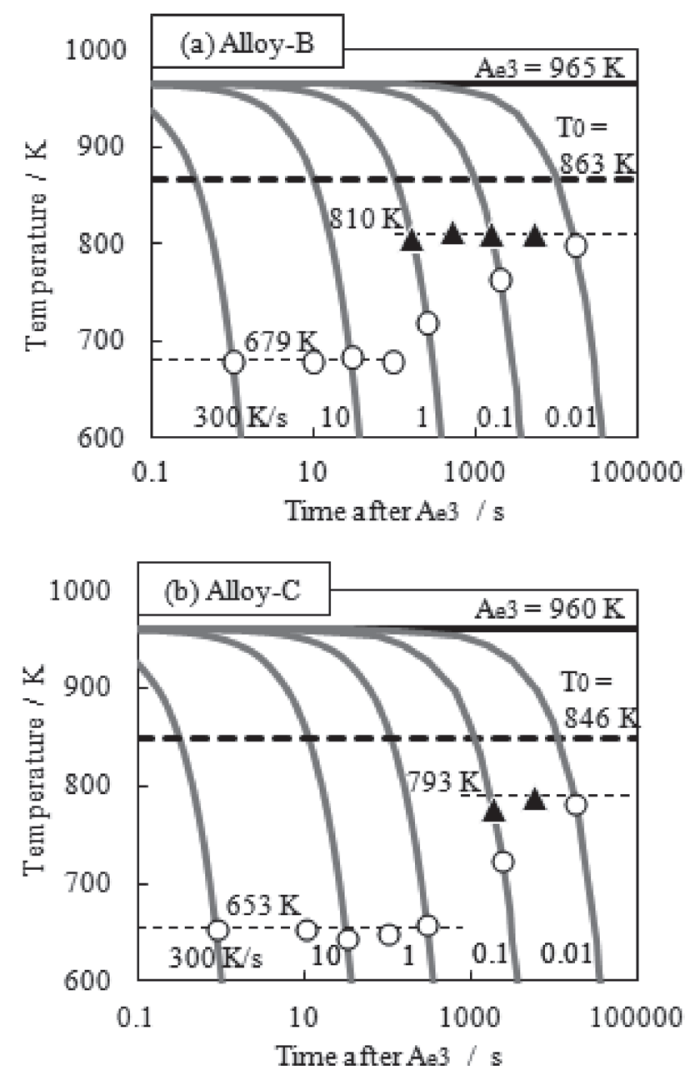

Fig. 6. CCT diagrams of boron-added low carbon alloys. The dots correspond to the transformation start point during continuous cooling after austenitization at $1473 \mathrm{~K}(\mathrm{O})$ and $1223 \mathrm{~K}(\mathbf{\Delta})$. 

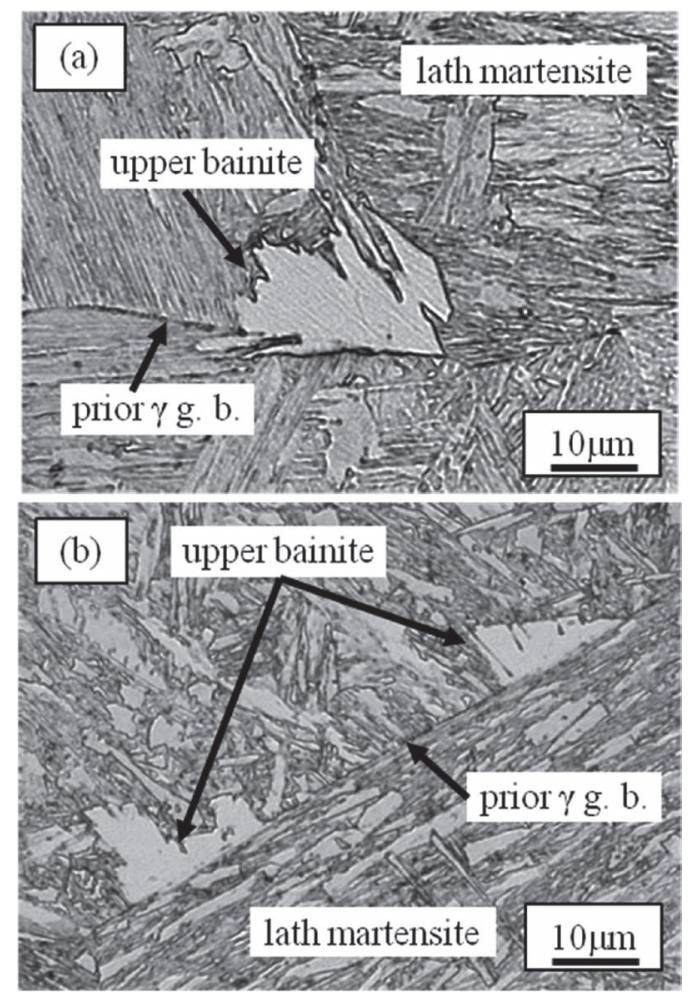

Fig. 7. OM images of boron-added low carbon alloys held isothermally: (a) Alloy B at $798 \mathrm{~K}$ for $1000 \mathrm{~s}$, and (b) Alloy C at $783 \mathrm{~K}$ for $10000 \mathrm{~s}$.

the $\mathrm{B}_{\mathrm{s}}$ of Alloys B and $\mathrm{C}$. Moreover, in these specimens, there is no allotriomorphic ferrite, film-like ferrite, and Widmanstätten ferrite.

\subsection{Low Carbon Fe-9Ni Alloys}

Figure 8 shows the CCT diagrams of Alloys D and E. In the CCT diagram, although $\mathrm{M}_{\mathrm{s}}$ is clear, it is difficult to determine the $\mathrm{B}_{\mathrm{s}}$ of alloy $\mathrm{D}$. Because the velocity of ferrite transformation in this alloy, which contains no boron, is faster than that in Alloy B containing boron, the terrace would be covered by the ferrite transformation start line in the CCT diagram. In the CCT diagram of Alloy E, although the terrace seems to be around $800 \mathrm{~K}$, it is not clear.

To clarify the $\mathrm{B}_{\mathrm{s}}$, we observed the microstructure in the early stage of transformation during isothermal holding. Figure 9 shows the OM images of Alloy D. In the Alloy D specimen held at $818 \mathrm{~K}$ for $3000 \mathrm{~s}$ (Fig. 9(a)), allotriomorphic ferrite was observed over a prior austenite grain boundary. On the other hand, in Fig. 9(b), which shows the microstructure at $808 \mathrm{~K}$, some upper bainite was observed around prior austenite grain boundaries along with allotriomorphic ferrite grains. This result proves that the $\mathrm{B}_{\mathrm{s}}$ of Alloy D is between $818 \mathrm{~K}$ and $808 \mathrm{~K}$.

Similarly, the OM observation results for Alloy $\mathrm{E}$ are shown in Fig. 10. In the specimen held at $808 \mathrm{~K}$, many allotriomorphic ferrite grains and no bainitic ferrite lath were observed. At $793 \mathrm{~K}$, the reconstructive ferrite was the main product in the early stage of transformation. However, there was a small amount of bainitic ferrite, which was generated at $793 \mathrm{~K}$, as shown in Fig. 10(b). The $\mathrm{B}_{\mathrm{s}}$ of Alloy E was between $808 \mathrm{~K}$ and $793 \mathrm{~K}$, probably close to $793 \mathrm{~K}$.

Figure 11 shows the TTT diagrams of Alloy D and E. The points in these diagrams express the transformation start
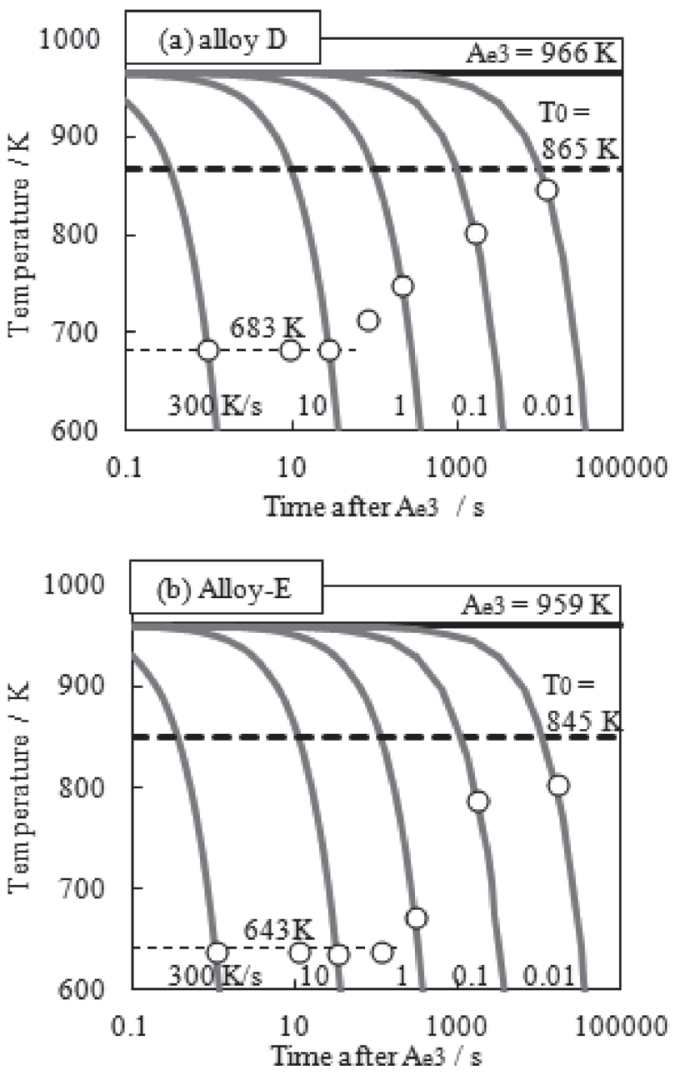

Fig. 8. CCT diagrams of Alloys D and E.
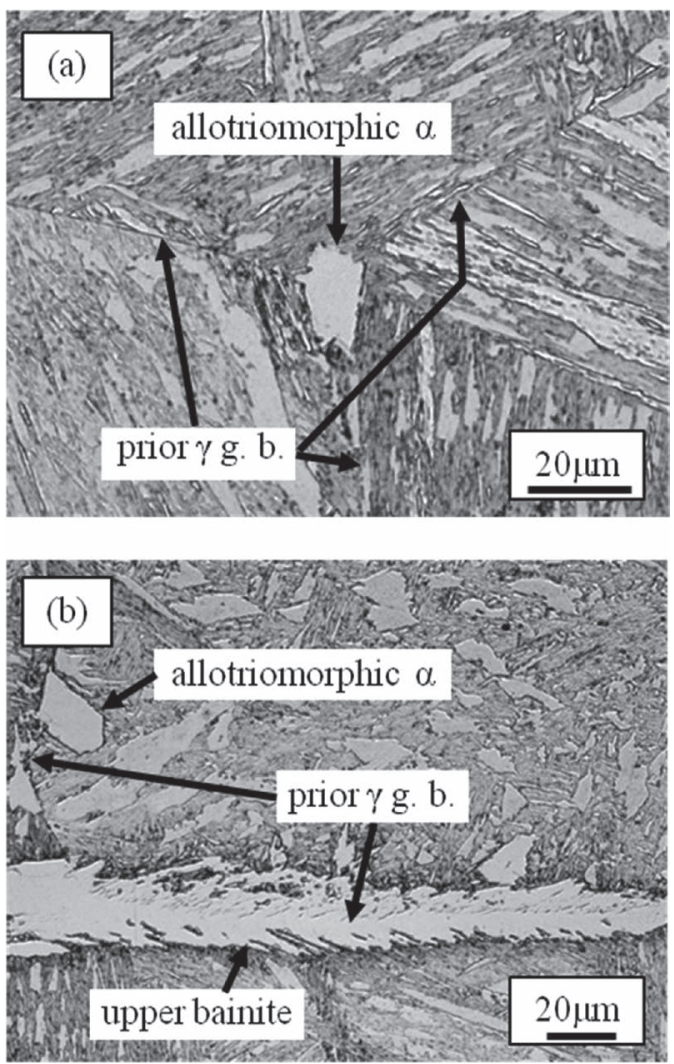

Fig. 9. OM images of the Alloy D specimen held isothermally (a) at $818 \mathrm{~K}$ for $3000 \mathrm{~s}$, and (b) at $808 \mathrm{~K}$ for $1000 \mathrm{~s}$.

times determined by dilatation curves. And their shapes correspond to the microstructure in the early stage of isothermal transformation. These TTT diagrams are similar to the 

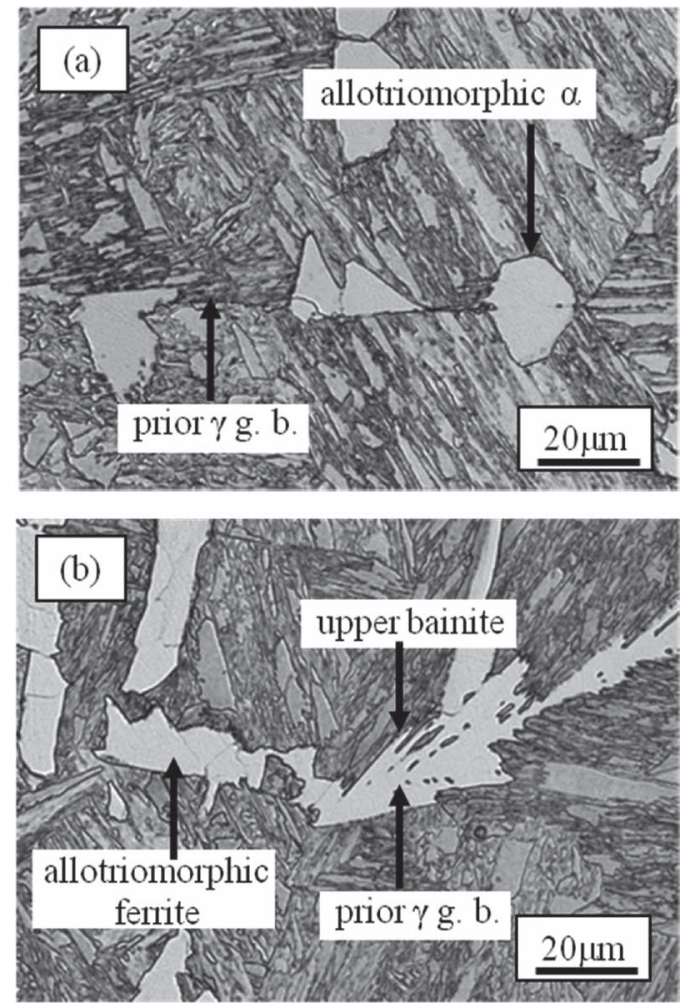

Fig. 10. OM images of the Alloy E samples held isothermally (a) at $808 \mathrm{~K}$ for $10000 \mathrm{~s}$, and (b) at $793 \mathrm{~K}$ for $1200 \mathrm{~s}$.
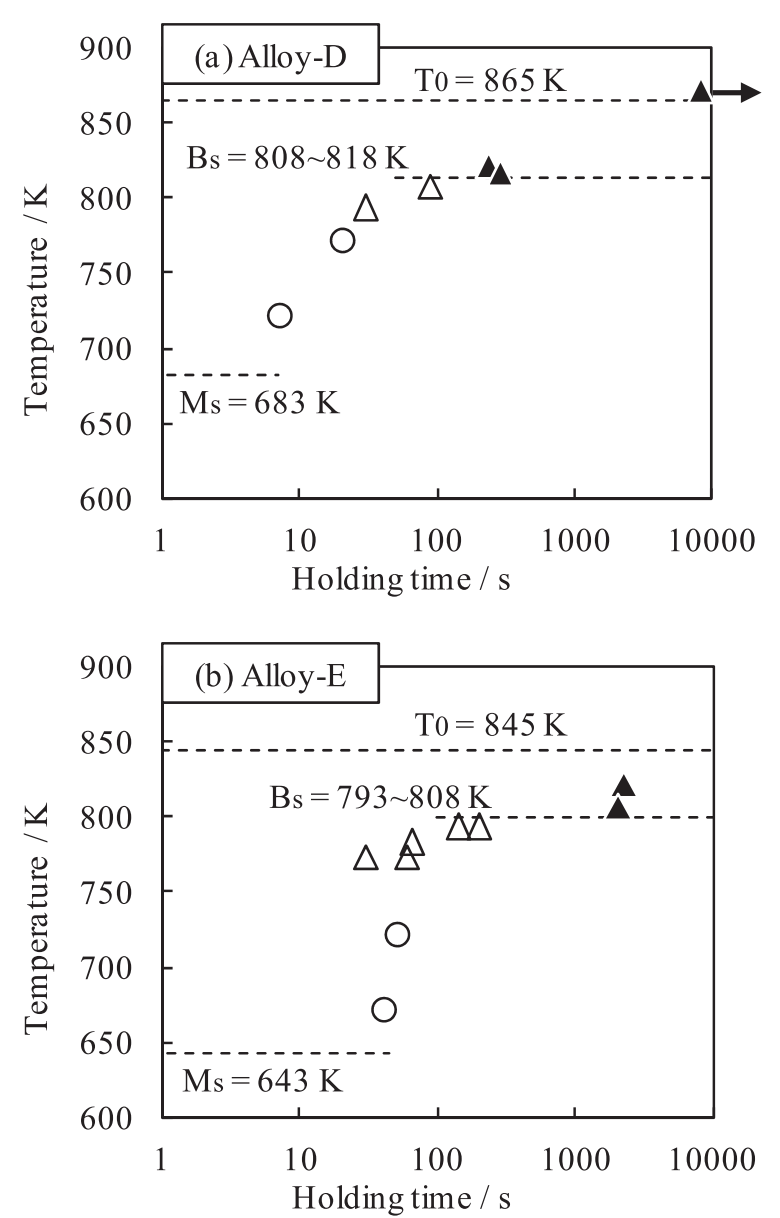

Fig. 11. TTT diagrams of Alloys D and E. The dots correspond to the transformation start point and the production of the transformation in the early stage. $\boldsymbol{\Delta}$ : ferrite, $\triangle$ : ferrite and bainite, $\circ$ : bainite. schematic TTT diagram shown in Fig. 1(c). In the microstructures just below $\mathrm{B}_{\mathrm{s}}$, bainitic ferrite is a minor structure when compared with the reconstructive ferrite structure, i.e., the structures of allotriomorphic ferrite, film-like ferrite, and Widmanstätten ferrite. This TTT diagram does not show a clear terrace and bay around $\mathrm{B}_{\mathrm{s}}$.

\subsection{Effect of Carbon Content on $B_{s}$}

Table 2 shows the $\mathrm{B}_{\mathrm{s}}$ of the alloys used herein. In the boron-added alloys, i.e. $\mathrm{A}, \mathrm{B}$ and $\mathrm{C}, \mathrm{B}_{\mathrm{s}}$ decreased with increasing carbon content from 0.003 mass $\%$ to 0.10 mass $\%$. In the boron-free alloys, the change of $B_{s}$ with the carbon content was not clear because the initial products just below $B_{s}$ were very complex, as shown in Figs. 9(b) and 10(b). However, it seems that $B_{s}$ decreased with increasing carbon content in the boron-free alloys, similarly.

As shown in Table 2, $\mathrm{M}_{\mathrm{s}}$ increased with decreasing carbon content, and the boron content had little or no effect on $\mathrm{M}_{\mathrm{s}}$. Alloy A, which contained 31 mass-ppm carbon showed the highest $\mathrm{M}_{\mathrm{s}}$, i.e., $765 \mathrm{~K}$; however, this value was lower than the $\mathrm{B}_{\mathrm{s}}$ of all the alloys used herein.

\section{Discussion}

We considered the mechanism of the relationship between $\mathrm{B}_{\mathrm{s}}$ and carbon content in terms of the driving force. Before the consideration, it was important to check the segregation of nickel in the specimens. The specimens were heated at $1473 \mathrm{~K}$ after cold rolling, and were quenched. Figure 12 shows the histograms of the nickel content measured via an electron probe microanalysis (EPMA). The histograms in 5 alloys resemble each other closely with respect to the positions and shapes. The nickel contents were distributed from 7 mass \% to 10 mass\% in all the alloys used herein.

Bainite and martensite transformations should start in nickel-poor regions. The detection accuracy of the transformation from fcc to bcc using the dilatation technique is $\sim 1 \%$ transformation rate, empirically. Therefore, we guessed that the effective nickel content for $\mathrm{B}_{\mathrm{s}}$ was the nickel content at $1 \%$ from the bottom of the distribution. Table 3 shows the effective nickel content $\mathrm{W}_{\mathrm{Ni}, \mathrm{E}}$, which is the nickel content in the nickel-poor region of each alloy. The temperatures $\mathrm{T}_{0, \mathrm{E}}$ in Table 3 were calculated as $\mathrm{T}_{0}$ temperatures using the nickel content at the nickel-poor regions $\left(\mathrm{W}_{\mathrm{Ni}, \mathrm{E}}\right)$.

Figure 13 shows the driving force of the partitionless transformation from fcc to bcc $(\Delta \mathrm{G})$ at $\mathrm{B}_{\mathrm{s}}$ and $\mathrm{M}_{\mathrm{s}}$ in Table 2. Open and solid points in Fig. 13 correspond to $\Delta \mathrm{G}$ at $\mathrm{B}_{\mathrm{s}}$ and $\mathrm{M}_{\mathrm{s}}$, respectively. Figure 13(a) shows $\Delta \mathrm{G}$ along with the chemical compositions of the alloys in Table $1 ; \Delta \mathrm{G}$

Table 2. $B_{s}$ and $M_{s}$ of the alloys used in this study.

\begin{tabular}{cccccc}
\hline Alloy & A & B & C & D & E \\
\hline Carbon/mass $\%$ & 0.0031 & 0.052 & 0.094 & 0.050 & 0.099 \\
Boron/mass $\%$ & 0.0023 & 0.0024 & 0.0024 & $<0.0003$ & $<0.0003$ \\
$\mathrm{~T}_{0} / \mathrm{K}$ & 884 & 863 & 846 & 865 & 845 \\
$\mathrm{~B}_{\mathrm{s}} / \mathrm{K}$ & 833 & 810 & 793 & $808-818$ & $793-808$ \\
$\mathrm{M}_{\mathrm{s}} / \mathrm{K}$ & 765 & 679 & 653 & 683 & 643 \\
\hline
\end{tabular}


corresponds to the supercooling from $\mathrm{T}_{0}$ in Table 1 . In this study, the $\Delta \mathrm{G}$ at $\mathrm{B}_{\mathrm{s}}$ did not depend on the carbon and boron content. All open points in Fig. 13(a) are along the constant energy line (dashed line). On the other hand, the $\Delta \mathrm{G}$ at $\mathrm{M}_{\mathrm{s}}$ increased with the carbon content and was not affected by the boron content.

Although Fig. 13(a) supposed homogenous alloys, all the alloys contain the Ni segregation shown in Fig. 12. $\Delta \mathrm{G}$ at $\mathrm{B}_{\mathrm{S}}$ should be calculated with $\mathrm{T}_{0, \mathrm{E}}$ and $\mathrm{W}_{\mathrm{Ni}, \mathrm{E}}$ in Table 3 . Figure 13(b) shows revised $\Delta \mathrm{G}$ at $\mathrm{B}_{\mathrm{s}}$ and $\mathrm{M}_{\mathrm{s}}$ for all the alloys. The values of $\Delta \mathrm{G}$ at $\mathrm{B}_{\mathrm{s}}$ were similar, i.e., $400 \mathrm{~J} / \mathrm{mol}$ represented by the dashed line in Fig. 13(b), regardless of the carbon and boron contents. This value is consistent with the driving force required for partitionless growth of ferrite, as proposed by Bhadeshia. ${ }^{1)}$ This consistency suggests that the detection of bainite transformation start requires the bainitic ferrite to grow rather than only nucleating.

If $\mathrm{B}_{\mathrm{s}}$ depends on the supercooling from $\mathrm{T}_{0}$, the bainite transformation progress in the specimen will vary owing to the nickel segregation. At the temperature just below $B_{s}$, the driving force in the nickel-rich region is not sufficient for
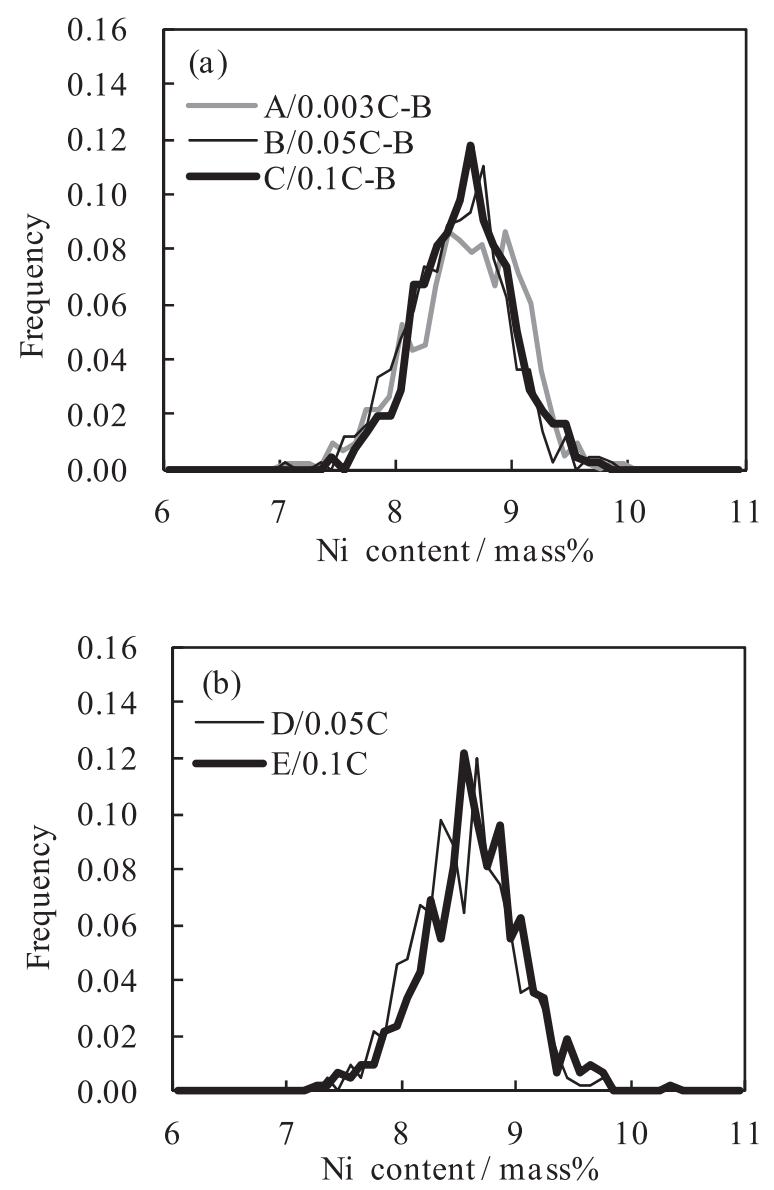

Fig. 12. Histograms of the local nickel content evaluated via EPMA for (a) the boron-added alloys and (b) the boronfree alloys.

Table 3. Effective nickel content and $T_{0}$ temperature for the bainite and martensite transformation start.

\begin{tabular}{cccccc}
\hline Alloy & A & B & C & D & E \\
\hline $\mathrm{W}_{\mathrm{Ni}, \mathrm{E}} / \mathrm{mass} \%$ & 7.40 & 7.49 & 7.62 & 7.50 & 7.42 \\
$\mathrm{~T}_{0, \mathrm{E}} / \mathrm{K}$ & 923 & 900 & 879 & 900 & 882 \\
\hline
\end{tabular}

the bainitic ferrite to grow without partitioning. Therefore, bainite transformation will progress partially in the specimen. In Alloy A, the addition of 1 mass $\%$ nickel reduces the driving force to $100 \mathrm{~J} / \mathrm{mol}$ at $\mathrm{B}_{\mathrm{s}}$. In order to obtain the driving force of $100 \mathrm{~J} / \mathrm{mol}$ extra, the supercooling degree of $19 \mathrm{~K}$ is further needed from $833 \mathrm{~K}$. It means that the local $B_{s}$ in the nickel-rich region is lower than the $B_{s}$ in the nickel-poor region.

Figure 14 shows the distribution of the local $B_{s}$ in Alloy A calculated with the consideration of nickel segregation shown in Fig. 12(a). In Fig. 14, at 823 K, 10\% austenite can
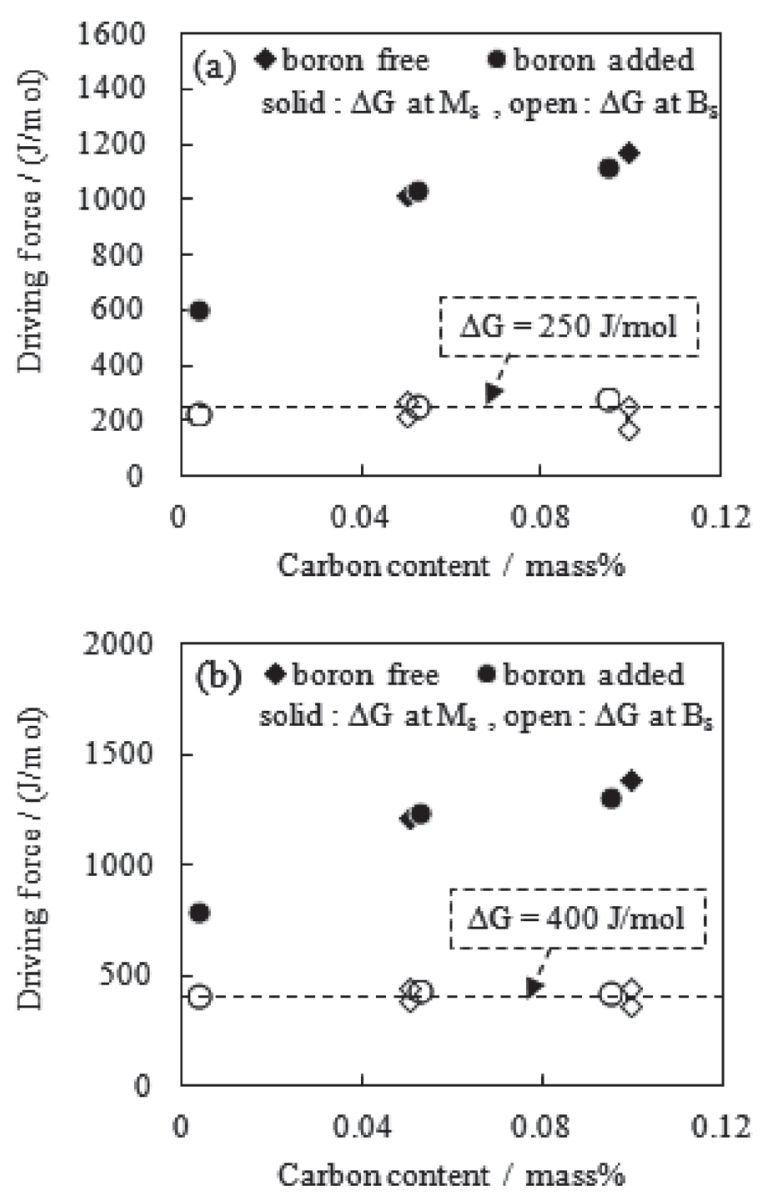

Fig. 13. Driving force for the partitionless transformation from fcc to bec at $B_{s}$ and $M_{s}$. (a) $\Delta G$ calculated using the bulk nickel content and (b) $\Delta \mathrm{G}$ calculated with the effective nickel content $\left(\mathrm{W}_{\mathrm{Ni}, \mathrm{E}}\right)$.

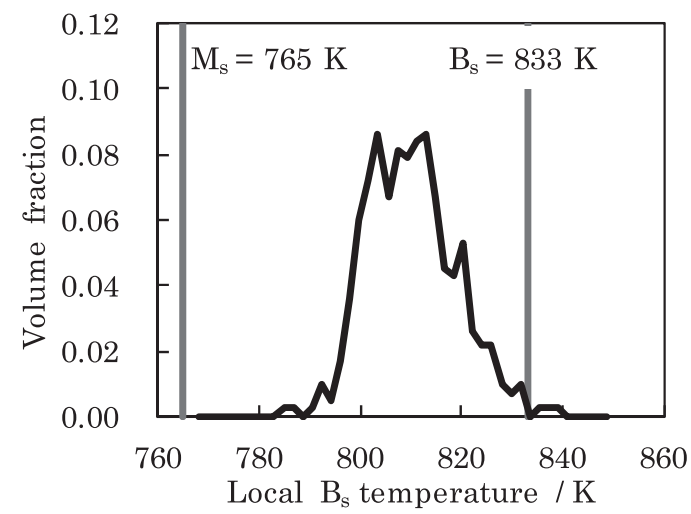

Fig. 14. Histogram of the local $B_{s}$ in Alloy A estimated considering nickel segregation. 
transform to bainite because its local $\mathrm{B}_{\mathrm{s}}$ is higher than 823 $\mathrm{K} ; 50 \%$ of austenite has a local $\mathrm{B}_{\mathrm{s}}$ temperature lower than $808 \mathrm{~K}$. Therefore, it is assumed that the half of the austenite will remain after the bainite transformation stops at $808 \mathrm{~K}$. This tendency corresponds to the incomplete transformation behavior in Alloy A shown in Fig. 4.

The incomplete transformation of bainite is generally explained by disappearance of the driving force occurring with the progress of bainite transformation. ${ }^{8)}$ However, the carbon content of Alloy A is very small, and the driving force hardly changes even when considering the increase of carbon. In this study, the reason for the incomplete transformation in the ultra low carbon alloy would be the effect of nickel segregation in the specimen.

Figure 15 shows the $B_{s}$ and $M_{s}$ evaluated in this study with the $\mathrm{A}_{3}, \mathrm{~T}_{0}$ and $\mathrm{T}_{0}$ ' lines for $\mathrm{Fe}-7.6$ mass $\% \mathrm{Ni}-\mathrm{C}$ ternary system. 7.6 mass $\% \mathrm{Ni}$ corresponds roughly to $\mathrm{W}_{\mathrm{Ni}, \mathrm{E}}$ of the alloys used herein (Table 3). $\mathrm{T}_{0}$ ' is the temperature at which the driving force of the partitionless transformation from fcc to bcc accounts for specific value. ${ }^{1,8)}$ The Bs expressed by open dots in Fig. 15 decreases with carbon increasing along with $\mathrm{T}_{0}$ ' at which the soopercooling from $\mathrm{T}_{0}$ is 400 $\mathrm{J} / \mathrm{mol}$. It indicate that the $\mathrm{B}_{\mathrm{s}}$ depends on the possibility of the partitionless growth of ferrite. ${ }^{1)}$ However, the nucleation behavior of bainite transformation is not clarified by the evaluation of $\mathrm{B}_{\mathrm{s}}$ in this study.

Tsuzaki et al. ${ }^{2)}$ proposed that the nucleation of bainitic ferrite occurs without partitioning in the local carbon-poor region and that the $B_{s}$ of the low carbon alloy matches the $\mathrm{M}_{\mathrm{s}}$ of the ultra low carbon alloy. In Alloy A, which contains 31 mass-ppm carbon, $B_{s}$ is $60 \mathrm{~K}$ higher than $\mathrm{M}_{\mathrm{s}}$. According to previous studies, ${ }^{22-24)}$ this carbon content can decrease

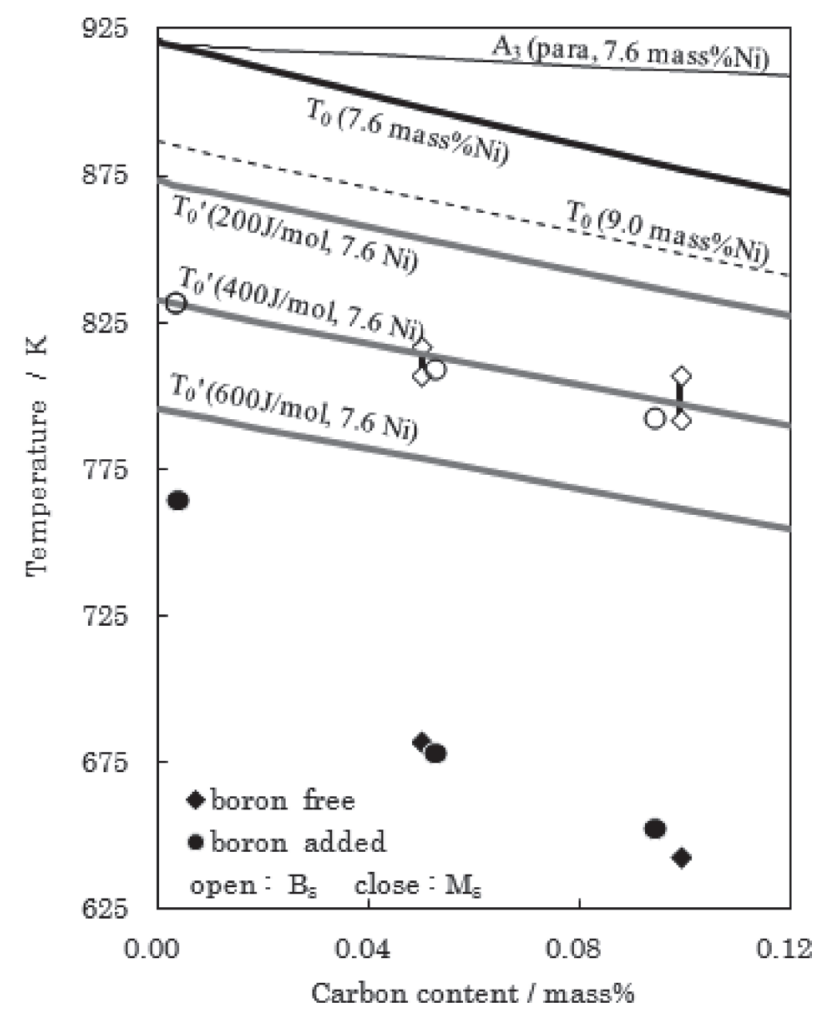

Fig. 15. $B_{s}$ and $M_{s}$ plotted on paraequilibrium $A 3 ; T_{0}$ and $T_{0}$ ' lines of the $\mathrm{Fe}-7.6$ mass $\% \mathrm{Ni}-\mathrm{C}$ ternary system. the $\mathrm{M}_{\mathrm{s}}$ by about $60 \mathrm{~K}$ in ultra low carbon $\mathrm{Fe}-\mathrm{C}$ alloys. The $B_{s}$ of carbon-free alloys may coincide with their $M_{s}$, which agrees with Tsuzaki's proposal about the nucleation of bainitic ferrite.

\section{Summary}

To clarify the effect of carbon content on the $\mathrm{B}_{\mathrm{s}}$ of low carbon Fe-9 mass\%Ni alloys, we prepared CCT and TTT diagrams and observed the microstructure in the early stage of transformation during isothermal holding. In this study, bainite refers to a lath-shaped ferrite group that generates over $\mathrm{M}_{\mathrm{s}}$.

(1) $B_{s}$ decreased with increasing carbon content from 0.003 to 0.10 mass $\%$.

(2) The $B_{s}$ values measured in this study were higher than $\mathrm{M}_{\mathrm{s}}$ in $\mathrm{Fe}-9$ mass $\% \mathrm{Ni}-0.002$ mass $\% \mathrm{~B}-0.003$ mass $\% \mathrm{C}$ alloy.

(3) Supercooling from the $T_{0}$ line at $B_{s}$ was constant in all specimens regardless of the amount of carbon and boron. The driving force of the partitionless transformation, calculated after considering nickel segregation, was approximately $400 \mathrm{~J} / \mathrm{mol}$.

\section{Acknowledgments}

The authors would like to express their sincere thanks to Dr. Goro Miyamoto (Tohoku University, Japan) for his valuable comments and stimulating discussions.

\section{REFERENCES}

1) H. K. D. H. Bhadeshia: Bainite in Steels, 2nd Ed., IOM Communications, London, (2001), 129.

2) K. Tsuzaki, K. Fujiwara and T. Maki : Mater. Trans. JIM, 32 (1991), 667.

3) H. I. Aaronson, H. A. Domian and G. M. Pound: Trans. Metall. Soc. AIME, 236 (1966), 753.

4) H. I. Aaronson, W. T. Reynolds, G. J. Shiflet and G. Spanos: Metall. Trans. A, 21A (1990), 1343.

5) W. T. Reynolds, F. Z. Li, C. K. Shui and H. I. Aaronson: Metall. Trans. A, 21A (1990), 1433.

6) H. Goldenstein and H. I. Aaronson: Metall. Trans. A, 21A (1990), 1465.

7) W. T. Reynolds, S. K. Liu, S. Hartfield and H. I. Aaronson: Metall. Trans. A, 21A (1990), 1479.

8) T. Furuhara, T. Yamaguchi, G. Miyamoto and T. Maki: Mater. Sci. Technol., 26 (2010), 392.

9) Y. Ohmori, H. Ohtsubo, Y. C. Jung, S. Okaguchi and H. Ohtani: Metall. Mater. Trans. A, 25A (1994), 1981.

10) D. Q. Bai, S. Yue, T. M. Maccagno and J. J. Jonas: ISIJ Int., 38 (1998), 371.

11) J. Wang, P. J. Van Der Wolk and S. Van Der Zwaag: J. Mater. Sci., 35 (2000), 4393.

12) X. Liang and A. J. Deardo: Metall. Mater. Trans. A, 45A (2014), 5173 .

13) G. J. Shiflet and H. I. Aaronson: Metall. Trans. A, 21A (1990), 1413.

14) S. M. C. van Bohemen: Mater. Sci. Technol., 28 (2012), 487.

15) L. C. Chang: Metall. Mater. Trans. A, 30A (1999), 909.

16) C. Garcia-Mateo and H. K. D. H. Bhadeshia: Mater. Sci. Eng., 378 (2004), 289.

17) G. Spanos, H. S. Fang, D. S. Sarma and H. I. Aaronson: Metall. Trans. A, 21A (1990), 1391.

18) Y. Ohmori, Y.-C. Jung, K. Nakai and H. Shioiri: Acta Mater., 49 (2001), 3149.

19) Y. Ohmori, H. Ohtani and T. Kunitake: Trans. Iron Steel Inst. Jpn., 11 (1971), 250.

20) S. Morito, H. Tanaka, R. Konishi, T. Furuhara and T. Maki: Acta Mater., 51 (2003), 1789.

21) T. Furuhara, H. Kawata, S. Morito and T. Maki: Mater. Sci. Eng. A, 431 (2006), 228.

22) M. J. Bibby and J. G. Parr: J. Iron Steel Inst., 202 (1964), 100.

$23)$ R. J. Ackert and J. G. Parr: J. Iron Steel Inst., 209 (1971), 912.

24) E. A. Wilson: ISIJ Int., 34 (1994), 615. 